\title{
Factors predicting clinical outcomes of endoscopic submucosal dissection in the rectum and sigmoid colon during the learning curve
}

Authors

Institution
Mikhail Agapov, Ekaterina Dvoinikova

Vladivostok Clinical Railway Hospital - Endoscopy, Vladivostok, Russian Federation submitted 24. March 2014 accepted after revision 23. June 2014

\section{Bibliography}

Dol http://dx.doi.org/ 10.1055/s-0034-1377613 Published online: 25.9.2014 Endoscopy International Open 2014; 02: E235-E240

(c) Georg Thieme Verlag KG Stuttgart · New York E-ISSN 2196-9736

\section{Corresponding author} Mikhail Agapov Vladivostok Clinical Railway Hospital - Endoscopy Verhneportovaya, 25 Vladivostok 690003 Russian Federation Fax: +7-4232-248227 magapov@hotmail.com
Background and study aims: Colorectal endoscopic submucosal dissection (ESD) is associated with significant technical difficulty, long procedure time, and increased risk of complications, especially perforation. This study aimed to determine the factors associated with clinical results of ESD during the learning curve.

Patients and methods: In total, 44 patients with sessile and flat rectal and sigmoid colon lesions underwent ESD from November 2009 to September 2013. The procedure time, resection method, tumor size, location, gross morphology, presence of fibrosis, histologic findings, rates of en bloc and piecemeal resections and perforation were analyzed. The ESD procedure was classified as technically difficult in the case of procedure time $>120$ minutes and/or piecemeal resection. The whole study time was divided into two periods: first period: resections $1-22$, second period: resections $23-44$.

\section{Introduction}

Colorectal cancer is one of the most commonly diagnosed malignancies in Western countries and represents a major cause of morbidity and mortality associated with cancer [1]. Detection and endoscopic resection of early stage colorectal tumors as well as precursor lesions is a well established approach to prevention and treatment of colorectal cancer. Endoscopic mucosal resection (EMR) is usually used for endoscopic removal of flat and sessile lesions of the large bowel. For tumors measuring $\geq 20 \mathrm{~mm}$, EMR often results in one piecemeal resection [2,3]. Piecemeal resection complicates proper morphological evaluation of the specimens removed. It is especially difficult to determine the lateral spread of the tumor to ensure complete removal. Piecemeal resection is associated with a higher rate of local tumor recurrence in comparison with en bloc EMR [2 -4].
Results: En bloc and R0 resection have been achieved in $84.1 \%$ of lesions. The mean procedure time was $119.95 \pm 11.22$ minutes (range 25-360 minutes). Perforation was seen in five cases (11.4\%). A larger tumor size was a risk factor for difficult ESD $(P=0.0001)$. A finding of fibrosis was a risk factor for piecemeal $\operatorname{ESD}(P=$ $0.0074)$, and perforation $(P=0.0012)$. There was a high direct positive correlation between tumor size and operation time $(r=0.83, P<0.0001,0.95$ and 0.99 confidence interval for rho $0.71-0.904$ ). There was no significant difference between the first and second period in terms of mean procedure time, en bloc resection or complication rate. Conclusion: A larger tumor size was associated with technically difficult ESD. Severe submucosal fibrosis was a risk factor for both piecemeal resection and perforation.

Endoscopic submucosal dissection (ESD) is a novel therapeutic procedure with the major advantage being its ability to achieve a high level of en bloc resection and low level of local recurrence for flat and sessile colorectal lesions regardless of size. On the other hand, colorectal ESD is associated with significant technical difficulty, longer procedure time, and increased risk of complications, especially perforations, in comparison with EMR $[5,6]$. Colorectal ESD is considered to be a more difficult and "dangerous" procedure than gastric ESD. In Japan, it is necessary to gain experience in gastric ESD before starting to practice ESD in the colon, usually under the supervision of an expert $[7,8]$. In Western countries, it is very difficult to follow the same learning pattern because of the different epidemiological situation (the incidence of gastric cancer is higher in Japan and a lower percentage of cancers are diagnosed at an early stage in the West) and the very limited number of practitioners with expertise in colorec- 
tal ESD [8]. This situation makes colorectal ESD uncommon in Western countries.

Several factors have been implicated in an increased risk of incomplete or complicated dissection $[9,10]$.

It is important to establish a better approach to the difficulties of implementing colorectal ESD during the learning period in Western settings, as well as the factors associated with the risk of complications. We report our experience with ESD for sessile and flat rectal and sigmoid colon lesions in a high-volume center in Russia.

\section{Methods}

$\nabla$

During the period from November 2009 to September 2013, 44 patients with sessile and flat rectal and sigmoid colon lesions underwent ESD at the Department of Endoscopy, Vladivostok Clinical Railway Hospital (Russia). The clinical indications for ESD included sessile and flat rectal and sigmoid colon lesions with one of the following features: (1) tumor size $\geq 20 \mathrm{~mm}$; (2) tumor recurrence after previous EMR.

The study was retrospective. All of the relevant data have been taken from the standard ESD protocol adopted by the department.

The morphology of lesions was determined according to the Paris classification. Lesion size has been estimated by comparison with the span of open ( $7 \mathrm{~mm}$ ) biopsy forceps (FB-24U-1; Olympus, Japan). The location was estimated from anatomic landmarks.

The colonic preparation was achieved by administration of a split-dose (2 and 2 liters) of Macrogol 4000 solution (Beaufour Ipsen International, France) before the procedure. All of the patients underwent conscious sedation using the intravenous administration of propofol and analgesia with fentanyl.

One endoscopist with experience in endoscopic mucosal resection in the large bowel (more than 200 cases) performed all procedures. Procedure time, tumor size and location, gross morphology, the presence of fibrosis, and morphological findings were analyzed. The main outcomes were en bloc and R0 resection rate, and number of perforations. For an analysis of the learning curve, the whole study time was divided into two periods: first period: resections $1-22$, second period: resections $23-44$.

The degree of submucosal fibrosis was classified into three types: F0, no fibrosis; F1; mild fibrosis; F2, severe fibrosis [10]. Total procedure time was defined as the time between the beginning of the submucosal injection and the completion of the dissection. Complications were classified as immediate (during the procedure) or delayed (after completion of the procedure). Perforation was defined as a hole in the muscle layer detectable endoscopically with free air outside the colonic lumen demonstrated on image studies. Bleeding was considered clinically relevant in the case of a hemoglobin drop $\geq 1 \mathrm{~g} / \mathrm{dL}$.

The ESD procedure was classified as technically difficult in the case of procedure time $>120$ minutes and/or piecemeal resection.

ESD procedures were conducted with a gastroscope (EG-530D, Fujifilm Europe GmbH, Germany) with a disposable distal attachment (D-201, Olympus, Japan or DH-28GR, 29CR; Fujifilm Medical Co., Japan) on the tip. A VIO 200D electrosurgical unit (ERBE Elektromedizin, Germany) was used for electrical cutting and coagulation. Carbon dioxide insufflation with a GW-1 delivery system (Fujifilm Europe GmbH, Germany) was used in all ESD cases.
A $10 \%$ glycerin solution was used for submucosal injections using a 21-gauge injection needle (NM-400L-0421, Olympus, Japan) outside the tumor margin.

A Flush knife or Flush knife-BT with a 2.0-mm-long tip (Fujifilm Europe $\mathrm{GmbH}$, Germany) connected to a waterjet pump was used to perform all steps in the ESD procedure: mucosal cut ("Endo Cut I" regime, Effect 2, Duration 3, Interval 3), submucosal dissection ("Forced Coag" regime, Effect 2, 40 W), and small-vessel coagulation ("Soft Coagulation" regime, Effect 7, 100W). Submucosal injection of $10 \%$ glycerin solution (via injection needle) and waterjet injection of saline solution using the Flush knife were repeated during the procedure to maintain sufficient submucosal elevation during the procedure. A hemostatic forceps (Coagrasper, FD411UR, Olympus) was used to prevent or stop significant bleeding from large vessels and to coagulate visible vessels in the postprocedure ulcer base ("Soft Coagulation" regime, Effect 5, 100W). The typical ESD procedure is shown in Video 1.

The specimen was stretched and pinned onto a hard plate before being sent to the pathology department. Histological evaluation was performed according to the standard principles for colorectal EMR and ESD specimens [11]. The pathological diagnosis was based on the Vienna classification of gastrointestinal epithelial neoplasia [12]. En bloc resection was defined as when the lesion was resected as a whole piece, and $\mathrm{R} 0$ resection was when the resected specimen was revealed to be free of tumor in both vertical and lateral margins.

Follow-up colonoscopy was planned 3 months after ESD. Local recurrence was defined as a histopathologically confirmed neoplastic lesion found at the site of the ESD scar.

All patients received detailed information about the procedure, alternative approaches, risks of complications and additional surgery, and provided written informed consent before participating in any protocol-specific procedures.

All data were analyzed using the chi-squared test and Fisher's exact tests. For lesion size and procedure time, ANOVA analysis was used. $P<0.05$ was considered to be statistically significant. The Pearson correlation coefficient was used to measure the strength of the association between two variables.

\section{Results}

$\nabla$

Forty-four patients took part in the study (23 men, 21 women). The mean age of the patients was $63.84 \pm 1.46$ years (range 41 82 years). The mean size of the tumors was $34.77 \pm 3.26 \mathrm{~mm}$ (range $10-120 \mathrm{~mm}$ ). All tumors were situated in the rectum or sigmoid colon. According to the Paris classification, there were 29 flat and 15 sessile (0-Is) tumors. Correlation between the serial number of the ESD procedure and both the tumor size and procedure time was weak ( $r=0.19$ and 0.17 , respectively).

- Table 1 shows the tumor characteristics, resection rates, and procedure time during the two study periods. In 37 cases (84.1\%), lesions were resected en bloc and R0 resection was achieved in all those cases. Four tumors were removed in two

\section{Video 1}

Typical endoscopic submucosal dissection (ESD) procedure.

online content including video sequences viewable at: www.thieme-connect.de 
Table 1 Tumor characteristics and characteristics of endoscopic submucosal dissection (ESD) procedure in the two study periods.

\begin{tabular}{|c|c|c|c|c|}
\hline & & First period $(n=22)$ & Second period $(n=22)$ & $P$-value \\
\hline \multicolumn{5}{|l|}{ Tumor characteristics } \\
\hline Mean tumor size $(\mathrm{mm})$ & & $32.72 \pm 5.11$ & $36.81 \pm 4.12$ & n.s. \\
\hline \multirow[t]{2}{*}{ Paris type } & $\begin{array}{l}\text { Sessile } \\
(n=15)\end{array}$ & 6 & 9 & \multirow[t]{2}{*}{ n.s. } \\
\hline & $\begin{array}{l}\text { Flat } \\
(n=29)\end{array}$ & 16 & 13 & \\
\hline \multirow[t]{2}{*}{ Location } & $\begin{array}{l}\text { Rectum } \\
(n=19)\end{array}$ & 12 & 7 & \multirow[t]{2}{*}{ n.s. } \\
\hline & $\begin{array}{l}\text { Sigmoid colon } \\
(n=25)\end{array}$ & 10 & 15 & \\
\hline \multirow[t]{3}{*}{ Morphology } & $\begin{array}{l}\text { LGD } \\
(n=10)\end{array}$ & 7 & 3 & \multirow[t]{3}{*}{ n.s. } \\
\hline & $\begin{array}{l}\text { HGD } \\
(n=22)\end{array}$ & 10 & 12 & \\
\hline & Cancer $(n=12)$ & 5 & 7 & \\
\hline \multirow[t]{2}{*}{ Fibrosis } & $\mathrm{F} 0-1$ & 19 & 18 & \multirow[t]{2}{*}{ n.s. } \\
\hline & $\mathrm{F} 2$ & 3 & 4 & \\
\hline \multicolumn{5}{|c|}{ ESD procedure characteristics } \\
\hline Mean procedure time (min) & & $101.85 \pm 11.74$ & $136.47 \pm 18.18$ & n.s. \\
\hline En bloc resection & & 20 & 17 & n.s. \\
\hline Perforation & & 3 & 2 & n.s. \\
\hline Recurrence & & 0 & 0 & n.s. \\
\hline
\end{tabular}

LGD, low grade dysplasia; HGD, high grade dysplasia.

fragments, and three tumors in three to four fragments. The mean size of the lesions removed in piecemeal fashion was higher than that for tumors resected en bloc, $44.0 \pm 4.55 \mathrm{~mm}$ and $33.03 \pm 3.73 \mathrm{~mm}$, respectively, but the difference was not statistically significant $(P=0.22)$. Histological examination revealed low grade dysplasia, high grade dysplasia and cancer in 10,22 , and 12 cases, respectively.

The mean procedure time was $119.95 \pm 11.22$ minutes (range 25-360 minutes). There was a high direct positive correlation between tumor size and operation time $(r=0.83, P<0.0001,0.95$ and 0.99 confidence interval for rho $0.71-0.904$ ). Operation time was shorter in the en bloc resection group than in the piecemeal group, $108.75 \pm 12.03$ minutes and $179.14 \pm 19.85$ minutes, respectively $(P=0.019)$. The mean procedure time did not differ between the first and second 22 ESD interventions: 101.85 \pm 11.74 minutes and $136.47 \pm 18.18$ minutes, respectively $(P=0.12)$. Severe, mild and absent submucosal fibrosis were diagnosed in $15.9 \%, 15.9 \%$, and $68.2 \%$ of cases, respectively. Tumor size was not a significant predictor of severe fibrosis, although the mean size of the lesions with F2 fibrosis was higher than that for tumors with F0 - F1 fibrosis, $40.0 \pm 5.34 \mathrm{~mm}$ and $33.78 \pm 3.74 \mathrm{~mm}$, respectively $(P=0.49)$. Three out of seven F2 tumors were flat (two LST-NG (laterally spreading tumor, non-granular type) and one IIa) and four were sessile (Is). One lesion (LST-NG) was situated on the anastomotic site and in one case (IIa), there was a recurrence after unsuccessful EMR.

Severe submucosal fibrosis was diagnosed in four out of seven cases of piecemeal ESD and in three cases of en bloc resection $(P=$ 0.0074 ). The procedure in patients with F0-F1 fibrosis was shorter than in patients with F2 fibrosis, $111.75 \pm 12.22$ minutes and $162.28 \pm 23.88$ minutes, respectively, but the difference did not reach the level of statistical significance $(P=0.093)$.

Complications occurred in seven cases (five perforations and two bleedings). All cases of perforation were diagnosed during the procedure and were successfully treated with endoscopic clip- ping. A sigmoid colon perforation treated with endoclips is shown in $\bullet$ Fig. 1.

Three perforations occurred during the first half and two during the second half of the ESD procedures. There was no difference between procedures complicated by perforation and uneventful ESD by tumor size $(31.0 \pm 6.0 \mathrm{~mm}$ and $35.25 \pm 3.61 \mathrm{~mm}$, respectively $P=0.68)$ and resection time $(104.0 \pm 23.48$ minutes and $122.0 \pm 12.35$ minutes, respectively $P=0.62$ ). At the same time, severe submucosal fibrosis was diagnosed in four out of five cases complicated by perforation and in three cases of uneventful ESD $(P=0.0012)$. Table 2 shows the comparison of tumor and procedure characteristics in patients with and without perforations associated with the ESD procedure.

In total, 19 procedures (43.1\%) were classified as technically difficult due to the following factors: procedure time $>120$ minutes, 12 patients; combination of procedure time $>120$ minutes and piecemeal resection, six patients; and piecemeal resection, one patient. Mean tumor size was significantly larger in the difficult ESD group compared with the standard ESD group, 48.31 \pm 5.96 and $24.48 \pm 1.75 \mathrm{~mm}$, respectively $(P=0.0001)$. The majority of difficult ESD procedures were performed for tumors of the sigmoid colon, but the difference did not reach a level of significance $(P=0.06)$. Table 3 shows a comparison of the tumor characteristics in the standard and difficult ESD groups.

No cases of clinically significant intraprocedural or postprocedural hemorrhage were noted. There were two cases of self-limited postprocedural hemorrhage, and no cases of surgery or death associated with complications of ESD. All patients underwent follow-up endoscopy 3 months after ESD. There was no local recurrence or stricture formation. Two patients had cancer with submucosal invasion $>1 \mathrm{~mm}$ and one had a blood vessel invasion. All of them were referred for surgical treatment. 

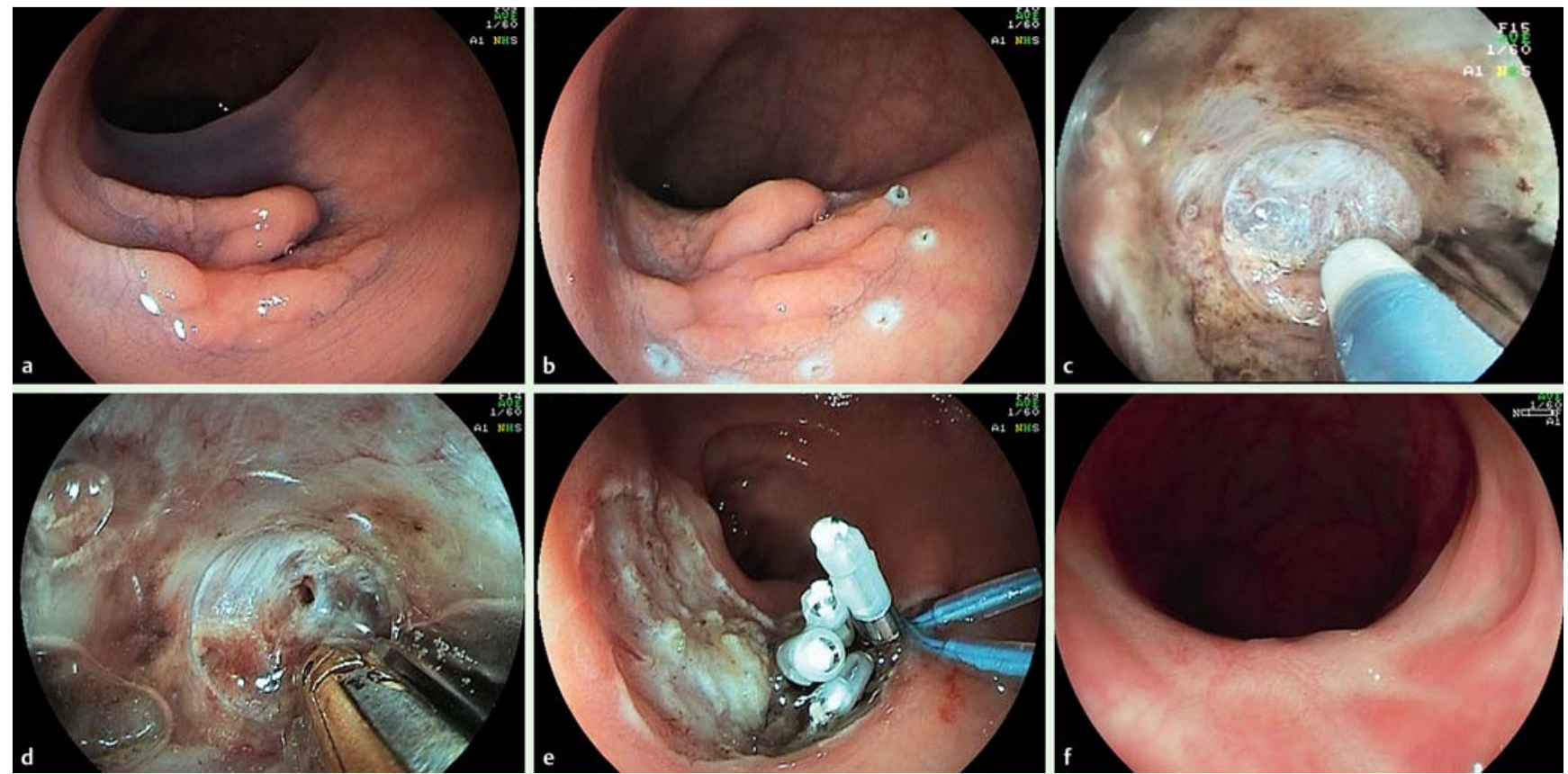

Fig. 1 Endoscopic submucosal dissection (ESD) in the sigmoid colon. a Laterally spreading tumor, non-granular, pseudo-depressed type (LST-NG-PD) in the sigmoid colon; $\mathbf{b}$ marking around the tumor borders; $\mathbf{c}$ dissection of the submucosa (F2 fibrosis); $\mathbf{d}$ visible perforation hole; $\mathbf{e}$ perforation was closed with clips and endoloops; $\mathbf{f}$ scar 4 months later.

\begin{tabular}{|c|c|c|c|c|}
\hline & & No perforation $(n=39)$ & Perforation $(n=5)$ & $P$-value \\
\hline \multicolumn{5}{|c|}{ Tumor characteristics } \\
\hline \multicolumn{2}{|c|}{ Mean tumor size $(\mathrm{mm})$} & $35.25 \pm 3.61$ & $31.0 \pm 6.0$ & n.s. \\
\hline \multirow[t]{2}{*}{ Paris type } & $\begin{array}{l}\text { Sessile } \\
(n=15)\end{array}$ & 13 & 2 & \multirow[t]{2}{*}{ n.s. } \\
\hline & $\begin{array}{l}\text { Flat } \\
(n=29)\end{array}$ & 26 & 3 & \\
\hline \multirow[t]{2}{*}{ Location } & $\begin{array}{l}\text { Rectum } \\
(n=19)\end{array}$ & 17 & 2 & \multirow[t]{2}{*}{ n.s. } \\
\hline & $\begin{array}{l}\text { Sigmoid colon } \\
(n=25)\end{array}$ & 22 & 3 & \\
\hline \multirow[t]{2}{*}{ Fibrosis } & $\begin{array}{l}F 0-1 \\
(n=37)\end{array}$ & 36 & 1 & \multirow[t]{2}{*}{0.0012} \\
\hline & $\begin{array}{l}F 2 \\
(n=7)\end{array}$ & 3 & 4 & \\
\hline \multicolumn{2}{|c|}{ Mean procedure time ( $\mathrm{min}$ ) } & $122.0 \pm 12.35$ & $104.0 \pm 23.48$ & n.s. \\
\hline
\end{tabular}

Table 2 Risk factor for perforation associated with endoscopic submucosal dissection (ESD) procedure.

\section{Discussion}

$\nabla$

Endoscopic mucosal resection (EMR) is a well-established method for treatment of colorectal epithelial neoplasms. In lesions larger than $20 \mathrm{~mm}$ and in cases of severe submucosal fibrosis, EMR often results in piecemeal resection associated with the difficulties of histopathological assessment of R0 resection, the risk of incomplete resection and local recurrence [2-4]. Endoscopic submucosal dissection (ESD) is a relatively new technique that is now established in Japan for en bloc resection of large benign and early malignant lesions [13]. While ESD reduces local recurrence rates compared to EMR, it is technically challenging, risky, and time consuming $[5,6,14]$. Compared with gastric lesions, ESD in the colorectum is more difficult owing to anatomical featuresthin wall, peristalsis, and folds $[6,15]$.

Owing to its technical difficulty, complication risks, and relatively long learning curve, ESD for colorectal lesions is rarely used in
Western countries and EMR is currently the standard treatment. A step-by-step approach to accumulating experience in colorectal ESD is desirable for adopting this technique [7,8]. Before first attempting ESD in the large bowel, experience with at least 30 gastric ESD cases has been recommended in Japan $[16,17]$. In the West, opportunities to follow a Japanese ESD training algorithm are limited by the low rates of early gastric cancer $[8,18]$. At the same time, a number of authors have reported a relatively rapid learning curve and low complication rats for colorectal ESD [19-21]. Several factors, including tumor location and size as well as severe submucosal fibrosis have been implicated in an increased risk for incomplete or complicated dissection $[9,10]$. The incidence and implications of these factors during the learning curve have as yet not been well established.

In this single-center study, the results of 44 ESD procedures for rectal and sigmoid colon lesions have been described. All interventions have been performed by a single specialist with experi- 


\begin{tabular}{|c|c|c|c|c|}
\hline & & Standard ESD $(n=25)$ & $\begin{array}{l}\text { Difficult ESD } \\
(n=19)\end{array}$ & $P$-value \\
\hline \multicolumn{5}{|c|}{ Tumor characteristics } \\
\hline \multicolumn{2}{|c|}{ Mean tumor size (mm) } & $24.48 \pm 1.75$ & $48.31 \pm 5.96$ & 0.0001 \\
\hline \multirow[t]{2}{*}{ Paris type } & $\begin{array}{l}\text { Sessile } \\
(n=15)\end{array}$ & 8 & 7 & \multirow[t]{2}{*}{ n.s. } \\
\hline & $\begin{array}{l}\text { Flat } \\
(n=29)\end{array}$ & 17 & 12 & \\
\hline \multirow[t]{2}{*}{ Histology } & $\begin{array}{l}\text { Malignant } \\
(n=12)\end{array}$ & 8 & 4 & \multirow[t]{2}{*}{ n.s. } \\
\hline & $\begin{array}{l}\text { Benign } \\
(n=32)\end{array}$ & 17 & 15 & \\
\hline \multirow[t]{2}{*}{ Location } & $\begin{array}{l}\text { Rectum } \\
(n=19)\end{array}$ & 14 & 5 & \multirow[t]{2}{*}{ n.s. } \\
\hline & $\begin{array}{l}\text { Sigmoid colon } \\
(n=25)\end{array}$ & 11 & 14 & \\
\hline \multirow[t]{2}{*}{ Fibrosis } & $\begin{array}{l}F 0-1 \\
(n=37)\end{array}$ & 23 & 14 & \multirow[t]{2}{*}{ n.s. } \\
\hline & $\begin{array}{l}F 2 \\
(n=7)\end{array}$ & 2 & 5 & \\
\hline \multirow[t]{2}{*}{ Experience } & First 22 ESD & 14 & 8 & \multirow[t]{2}{*}{ n.s. } \\
\hline & Second 22 ESD & 11 & 11 & \\
\hline
\end{tabular}

Risk factor for technically difficult endoscopic submucosal dissection (ESD). ence in endoscopic mucosal resection in the large bowel and with limited experience (19 cases) of gastric ESD. The en bloc and R0 resection rates were the same $-84.1 \%$. These figures are lower than reported by authors from high volume Asian centers [14, $22,23]$, but comparable to en bloc and $\mathrm{R} 0$ resection rates according to European data [19,21,24].

Procedure time in the study (120 minutes) was much longer than reported by Japanese authors $[14,22,23]$. However, the current results are comparable to Western data presented by Probst et al. (172 minutes) [19] and Thorlacius et al. (142 minutes) [24]. Larger tumor size and piecemeal resection were associated with longer procedure times in the current series. Tumor size is regarded as one of the factors predicting the procedural time of ESD, at least for gastric lesions [25,26].

Inability to perform en bloc ESD usually reflects a difficult procedure that, in turn, leads to increased time required for the intervention [9].

In this study, severe submucosal fibrosis was the only risk factor for both piecemeal ESD and perforation. At the same time, larger tumor size was the single significant risk factor for technically difficult ESD. Almost two-thirds of difficult ESDs were performed for lesions of the sigmoid colon. Matsumoto et al. [10] reported that, in cases of lesions with severe (F2) fibrosis, the rate of complete en bloc resection was low, and did not improve significantly even with growing operator experience. Several studies have demonstrated that the presence of fibrosis is an independent risk factor for perforation during colorectal ESD [10, 27]. At the same time, tumor size and location are conceded by several authors to be factors associated with difficult ESD and increased risk of perforation $[9,28]$.

Several factors have been implicated as a cause of severe submucosal fibrosis: previous EMR attempts, multiple biopsies and inflammatory bowel disease. There are also reports that the macroscopic characteristics of the lesions can be used to predict the risk of fibrosis, but the results are still controversial. Different authors have suggested that the incidence of F2 fibrosis was higher in LST-G (laterally spreading tumor, granular type) [10] or LST-NG and large Is tumors [9].
In our series, F2 fibrosis was reliably predicted by patient's history (previous unsuccessful EMR) and characteristics of the lesion (tumor on the anastomosis site) in two cases. In another five cases of severe fibrosis, large ( $>40 \mathrm{~mm}$ in diameter) sessile lesions (four tumors) prevailed. A relatively long period of growth in combination with chronic traumatization due to peristaltic movements can explain the high risk of fibrosis in such lesions. The possible role of endoscopic biopsy has not been analyzed owing to lack of relevant data.

The number of perforations (11.4\%) in our study was high in comparison to most of the published data $(1.8-7.4 \%)[14,21$, $22]$. To the best of our knowledge, the highest level of perforations during colorectal ESD (20.4\%) was reported by Kim et al. [26]. The level of perforations would have been regarded as unacceptable if surgery had been required for correction. Fortunately, most perforations can be managed successfully with nonsurgical treatment $[14,22,23,27]$. This finding was confirmed in the current study.

We failed to show any difference in procedure time, en bloc resection rate as well as in the number of perforations between the first and second 22 interventions. Probst et al. reported that a clear learning curve was apparent over time, with resection rates increasing and procedure times decreasing significantly after the first 25 ESD procedures in the rectosigmoid [19]. According to Iacopini et al., the operating time per square centimeter significantly decreased after 20 ESD procedures [20]. At the same time, based on their analysis of 120 colorectal ESDs, Hotta et al. concluded that approximately 40 procedures were sufficient to acquire skill in avoiding perforations during the ESD procedure, and approximately 80 procedures must be carried out to acquire skill with ESD for large colorectal tumors [28]. According to Sakamoto et al., trainee endoscopists with experience in gastric ESD can perform it safely and independently in the colon after preparatory training and experience with $\geq 30$ cases. At the same time, the authors mentioned that the procedure time and en bloc resection rate were not significantly different among the training periods [29]. Saito et al. reported that the risk of perforation was related to the number of ESD procedures performed, that is, the 
risk is higher when the endoscopist had performed less than 100 procedures [30].

The main limitations of this study include the fact that it was a single center study and limited to lesions of the distal colon.

We can conclude that ESD in the distal colon is feasible, effective, and a relatively safe procedure for Western endoscopists. Despite the substantial rate of perforations, most of them can be managed successfully during the ESD procedure. Larger tumor size was the main risk factor for technically difficult procedures. Severe submucosal fibrosis was an important factor associated with a low rate of en bloc resection and a high risk of perforation during the learning curve for colorectal ESD. It might be reasonable to start with smaller lesions and avoid cases with predictable F2 fibrosis during the training period. Colorectal ESD is associated with a relatively long learning curve, and 22 ESD cases might not be sufficient to improve en bloc resection rates, reduce procedure times and the number of perforations during a further 22 resections. Prospective randomized trials comparing EMR and ESD are awaited in Europe to demonstrate the long-term results, the benefit of ESD over piecemeal EMR and also to determine the indications for ESD vs. EMR in different clinical settings.

\section{Competing interests: None}

\section{References}

1 Haggar FA, Boushey RP. Colorectal cancer epidemiology: incidence, mortality, survival, and risk factors. Clin Colon Rectal Surg 2009; 22: $191-197$

2 Hotta K, Fujii T, Saito Y et al. Local recurrence after endoscopic resection of colorectal tumors. Int J Colorectal Dis 2009; 24: 225-230

3 Tanaka S, Haruma K, Oka S et al. Clinicopathologic features and endoscopic treatment of superficially spreading colorectal neoplasms larger than 20 mm. Gastrointest Endosc 2001; 54: 62 -66

4 Santos CE, Malaman D, Pereira-Lima JC. Endoscopic mucosal resection in colorectal lesion: A safe and effective procedure even in lesions larger than $2 \mathrm{~cm}$ and in carcinomas. Arq Gastroenterol 2011; 48: $242-$ 247

5 Kobayashi N, Yoshitake N, Hirahara Y et al. Matched case-control study comparing endoscopic submucosal dissection and endoscopic mucosal resection for colorectal tumors. J Gastroenterol Hepatol 2012; 27: $728-733$

6 Yoshida N, Yagi N, Naito Yet al. Safe procedure in endoscopic submucosal dissection for colorectal tumors focused on preventing complications. World J Gastroenterol 2010; 16: 1688-1695

7 Uraoka T, Parra-Blanco A, Yahagi N. Colorectal endoscopic submucosal dissection: is it suitable in western countries? J Gastroenterol Hepatol 2013; $28: 406-414$

8 Coman RM, Gotoda T, Draganov PV. Training in endoscopic submucosal dissection. World J Gastrointest Endosc 2013; 5: 369-378

9 Inada $Y$, Yoshida $N$, Kugai $M$ et al. Prediction and treatment of difficult cases in colorectal endoscopic submucosal dissection. Gastroenterol Res Pract 2013: Article ID 523084

10 Matsumoto A, Tanaka S, Oba S et al. Outcome of endoscopic submucosal dissection for colorectal tumors accompanied by fibrosis. Scand J Gastroenterol 2010; 45: 1329-1337
11 Yoshida N, Naito Y, Yagi $N$ et al. Importance of histological evaluation in endoscopic resection of early colorectal cancer. World J Gastrointest Pathophysiol 2012; 3: 51-59

12 Dixon MF. Gastrointestinal epithelial neoplasia: Vienna revisited. Gut 2002; $51: 130-131$

13 Tanaka S, Terasaki M, Kanao $\mathrm{H}$ et al. Review current status and future perspectives of endoscopic submucosal dissection for colorectal tumors. Dig Endosc 2012; 24: 73-79

14 Toyonaga T, Man-i M, Chinzei $R$ et al. Endoscopic treatment for early stage colorectal tumors: The comparison between EMR with small incision, simplified ESD, and ESD using the standard flush knife and the ball tipped flush knife. Acta Chir Iugosl 2010; 57: 41 - 46

15 Tanaka S, Terasaki M, Hayashi $N$ et al. Warning for unprincipled colorectal endoscopic submucosal dissection: accurate diagnosis and reasonable treatment strategy. Dig Endosc 2013; 25: 107-116

16 Ohata $K$, Ito $T$, Chiba $H$ et al. Effective training system in colorectal endoscopic submucosal dissection. Dig Endosc 2012; 24: 84-89

17 Niimi K, Fujishiro M, Kodashima $S$ et al. Long-term outcomes of endoscopic submucosal dissection for colorectal epithelial neoplasms. Endoscopy 2010; 42: 723-729

18 Kaltenbach T, Soetikno R, Kusano C et al. Development of expertise in endoscopic mucosal resection and endoscopic submucosal dissection. Tech Gastrointest Endosc 2011; 13: 100-104

19 Probst A, Golger D, Anthuber $M$ et al. Endoscopic submucosal dissection in large sessile lesions of the rectosigmoid: Learning curve in a European center. Endoscopy 2012; 44: 660-667

20 Iacopini $F$, Bella $A$, Costamagna $G$ et al. Stepwise training in rectal and colonic endoscopic submucosal dissection with differentiated learning curves. Gastrointest Endosc 2012; 76: 1188-1196

21 Białek A, Pertkiewicz J, Karpińska K et al. Treatment of large colorectal neoplasms by endoscopic submucosal dissection: a European singlecenter study. Eur J Gastroenterol Hepatol 2014; 26: 607-615

22 Yoshida N, Naito Y, Kugai M et al. Efficient hemostatic method for endoscopic submucosal dissection of colorectal tumors. World J Gastroenterol 2010; 16: 4180-4186

23 Lee EJ, Lee JB, Lee SH et al. Endoscopic submucosal dissection for colorectal tumors - 1,000 colorectal ESD cases: one specialized institute's experiences. Surg Endosc 2013; 27: 31 - 39

24 Thorlacius $\mathrm{H}$, Uedo $\mathrm{N}$, Toth E. Implementation of endoscopic submucosal dissection for early colorectal neoplasms in Sweden. Gastroenterol Res Pract 2013: Article ID 758202

25 Goto $\mathrm{O}$, Fujishiro M, Kodashima $S$ et al. Is it possible to predict the procedural time of endoscopic submucosal dissection for early gastric cancer? J Gastroenterol Hepatol 2009; 24: 379-383

26 Ahn JY, Choi KD, Choi JYet al. Procedure time of endoscopic submucosal dissection according to the size and location of early gastric cancers: analysis of 916 dissections performed by 4 experts. Gastrointest Endosc 2011; 73: $911-916$

27 Kim ES, Cho KB, Park KS et al. Factors predictive of perforation during endoscopic submucosal dissection for the treatment of colorectal tumors. Endoscopy 2011; 43: 573-578

28 Hotta K, Oyama T, Shinohara T et al. Learning curve for endoscopic submucosal dissection of large colorectal tumors. Dig Endosc 2010; 22: $302-306$

29 Sakamoto T, Saito Y, Fukunaga S et al. Learning curve associated with colorectal endoscopic submucosal dissection for endoscopists experienced in gastric endoscopic submucosal dissection. Dis Colon Rectum 2011; 54: $1307-1312$

30 Saito Y, Uraoka T, Yamaguchi Yet al. A prospective, multicenter study of 1111 colorectal endoscopic submucosal dissections (with video). Gastrointest Endosc 2010; 72: 1217-1225 